\title{
Novel Arenavirus Isolates from Namaqua Rock Mice, Namibia, Southern Africa
}

\author{
Peter T. Witkowski, René Kallies, Julia Hoveka, \\ Brita Auste, Ndapewa L. Ithete, \\ Katarína Šoltys, Tomáš Szemes, \\ Christian Drosten, Wolfgang Preiser, \\ Boris Klempa, John K.E. Mfune, Detlev H. Kruger
}

Arenaviruses are feared as agents that cause viral hemorrhagic fevers. We report the identification, isolation, and genetic characterization of 2 novel arenaviruses from Namaqua rock mice in Namibia. These findings extend knowledge of the distribution and diversity of arenaviruses in Africa.

\begin{abstract}
$\mathrm{A}$ renaviruses are known to cause severe hemorrhagic fevers across the globe with case fatality rates up to $30 \%$ (1). The viruses possess a bisegmented, single-stranded RNA genome with ambisense coding strategy consisting of a small segment coding for the nucleoprotein and glycoprotein and a large (L) segment coding for the RNAdependent RNA polymerase and matrix protein.

In Africa, Lassa virus (LASV) and Lujo virus are the only known members of the family Arenaviridae that cause human disease $(2,3)$; however, evidence for lymphocytic choriomeningitis virus, another Arenaviridae sp., was recently reported in Gabon (4). Several other arenaviruses of unknown pathogenic potential have also been found in Africa: Gbagroube, Kodoko, and Menekre viruses from western Africa (5,6); Ippy (IPPYV) and Mobala viruses from central Africa; Mopeia, Morogoro, Luna, and Lunk viruses from eastern Africa; and Merino Walk virus (MWV) from southern Africa $(7,8)$. All of these viruses are carried by rodents of the family Muridae.

Until now, no molecular detection of arenaviruses has been reported from Namibia. A study in 1991 described a low seroprevalence $(0.8 \%)$ for LASV antibodies in humans in northern Namibia (9). Because of lack of data about arenavirus occurrence and effects in southwestern Africa, we
\end{abstract}

Author affiliations: Charité Medical School, Berlin, Germany (P.T. Witkowski, B. Auste, B. Klempa, D.H. Kruger); Helmholtz Centre for Environmental Research-UFZ, Leipzig, Germany (R. Kallies); University of Bonn Medical Center, Bonn, Germany

(R. Kallies, C. Drosten); University of Namibia, Windhoek,

Namibia (J. Hoveka, J.K.E. Mfune); Stellenbosch University and

National Health Laboratory Services Tygerberg, Cape Town,

South Africa (N.L. Ithete, W. Preiser); Comenius University,

Bratislava, Slovakia (K. Šoltys, T. Szemes); Slovak Academy of

Sciences, Bratislava (B. Klempa)

DOI: http://dx.doi.org/10.3201/eid2106.141341 conducted a study of small mammals from Namibia to detect infection with arenaviruses.

\section{The Study}

During 2010-2012, animal trapping was performed in 8 areas in central and northern Namibia (Figure 1), and samples from 812 rodents and shrews were obtained (Table 1). The animals were dissected in the field and stored individually in a field freezer at $-20^{\circ} \mathrm{C}$ and later at $-80^{\circ} \mathrm{C}$. For primary arenavirus screening, lung sections of all animals were homogenized, and RNA was extracted and reversely transcribed by using random hexamer primers. Screening was performed by arenavirus genus-specific reverse transcription PCR (RT-PCR) (10) to detect the L genomic segment. From samples testing positive by

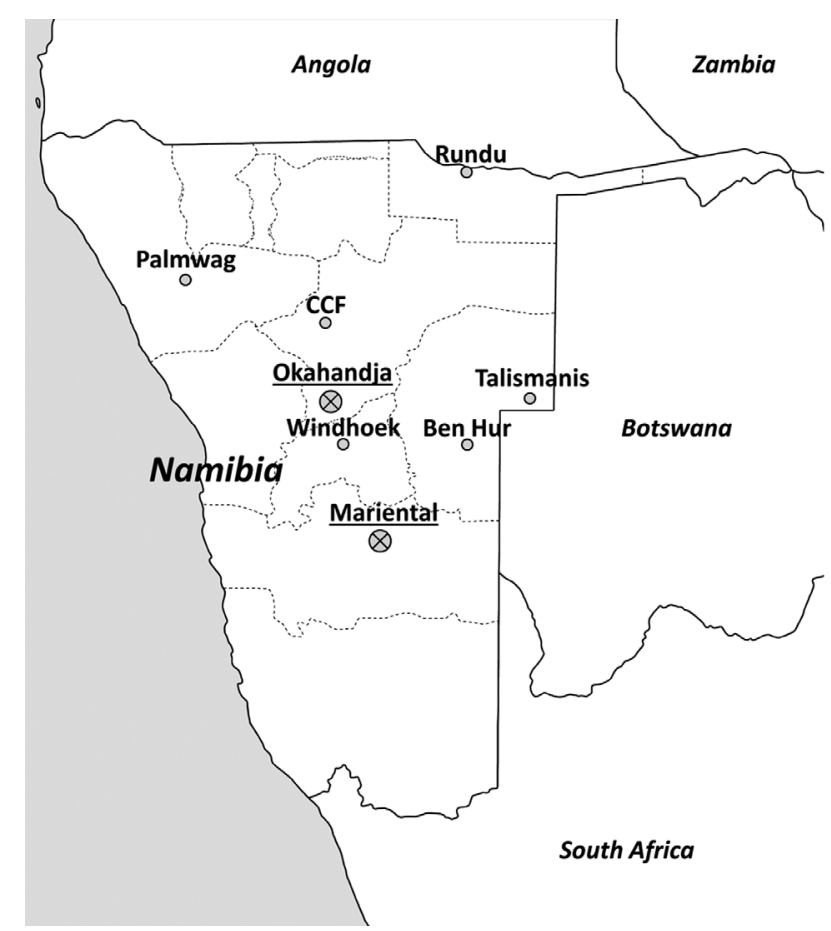

Figure 1. Screening for arenaviruses in Namibia. Trapping locations (named according to the nearest urban settlement) of small mammals. Sites where samples positive for new arenaviruses were found are marked by a crossed circle and underlined locality names. Geographic positioning system coordinates of the trapping sites: Ben Hur, $22^{\circ} 87.26^{\prime} \mathrm{S}$, $19^{\circ} 21.10^{\prime} \mathrm{E}$; Cheetah Conservation Fund (CCF), $16^{\circ} 39.0^{\prime} \mathrm{E}$, $20^{\circ} 28.12^{\prime} \mathrm{S}$; Mariental, $24^{\circ} 62.08^{\prime} \mathrm{S}, 17^{\circ} 95.93^{\prime} \mathrm{E}$; Okahandja, (21 $\left.{ }^{\circ} 98.33^{\prime} \mathrm{S}, 16^{\circ} 91.32^{\prime} \mathrm{E}\right)$; Palmwag, $19^{\circ} 53.23^{\prime} \mathrm{S}, 13^{\circ} 56.35^{\prime} \mathrm{E}$; Rundu, $17^{\circ} 56.645^{\prime} \mathrm{S}, 20^{\circ} 05.109^{\prime} \mathrm{E}$; Talismanis, $21^{\circ} 84.30^{\prime} \mathrm{S}$, $20^{\circ} 73.91^{\prime} \mathrm{E}$; Windhoek, $22^{\circ} 49.93^{\prime} \mathrm{S}, 17^{\circ} 34.76^{\prime} \mathrm{E}$. 
Table 1. Small mammals captured in Namibia during 2010-2012 and tested for arenaviruses*

\begin{tabular}{|c|c|c|c|}
\hline Mammal species & Common name & Localities of capture $†$ & No. positive/no. tested \\
\hline Aethomys chrysophilus & Red veld rat & $\mathrm{Be}, \mathrm{CCF}, \mathrm{Ok}, \mathrm{Pa}, \mathrm{Ta}$ & $0 / 64$ \\
\hline Micaelamys namaquensis & Namaqua rock mouse & CCF, Ma, Ok, Pa, Ru & $4 / 266$ \\
\hline Crocidura fuscomurina & Bicolored musk shrew & $\mathrm{CCF}, \mathrm{Pa}, \mathrm{Ru}$ & $0 / 4$ \\
\hline Crocidura hirta & Lesser red musk shrew & $\mathrm{Ma}$ & $0 / 5$ \\
\hline Dendromus melanotis & Gray climbing mouse & $\mathrm{Ta}$ & $0 / 1$ \\
\hline Elephantulus intufi & Bushveld sengi & $\mathrm{CCF}, \mathrm{Ma}, \mathrm{Ok}$ & $0 / 14$ \\
\hline Gerbilliscus spp. & Gerbil & Wi & $0 / 6$ \\
\hline Gerbilliscus leucogaster & Bushveld gerbil & $\mathrm{Be}, \mathrm{CCF}, \mathrm{Ma}, \mathrm{Ok}, \mathrm{Pa}, \mathrm{Ru}, \mathrm{Ta}$ & $0 / 228$ \\
\hline Gerbillurus paeba & Hairy-footed gerbil & $\mathrm{Be}$ & $0 / 3$ \\
\hline Gerbillurus setzeri & Namib brush-tailed gerbil & $\mathrm{Be}$ & $0 / 1$ \\
\hline Lemniscomys rosalia & Single-striped grass mouse & $\mathrm{Be}$ & $0 / 2$ \\
\hline Mastomys spp. & Multimammate mouse & $\mathrm{Be}, \mathrm{CCF}, \mathrm{Ma}, \mathrm{Ok}, \mathrm{Pa}, \mathrm{Ru}, \mathrm{Ta}$ & $0 / 114$ \\
\hline Mus indutus & Desert pygmy mouse & $\mathrm{Ma}, \mathrm{Pa}$ & $0 / 5$ \\
\hline Petromyscus collinus & Pygmy rock mouse & $\mathrm{Pa}$ & $0 / 3$ \\
\hline Rhabdomys pumilio & Four-striped grass mouse & $\mathrm{CCF}, \mathrm{Ma}, \mathrm{Pa}, \mathrm{Ok}, \mathrm{Wi}$ & $0 / 73$ \\
\hline Saccostomus campestris & Pouched mouse & $\mathrm{Be}, \mathrm{CCF}, \mathrm{Ok}, \mathrm{Pa}, \mathrm{Ru}$ & $0 / 17$ \\
\hline Thallomys paedulcus & Acacia rat & $\mathrm{Pa}$ & $0 / 4$ \\
\hline u.u. Soricidae & Shrew & Wi & $0 / 2$ \\
\hline Total & & & $4 / 812$ \\
\hline \multicolumn{4}{|c|}{$\begin{array}{l}\text { *Morphologic species identification of the arenavirus positive rodent samples was confirmed by sequencing of partial mitochondrial cytochrome b gene } \\
\text { (GenBank accession nos.: N27, KP752173; N73, KP752175; N80, KP752176; N85, KP752174). } \\
\text { †Abbreviations and sampling dates for trapping localities: Be, Ben Hur (11/2011); CCF, Cheetah Conservation Fund (02/2011); Ok, Okahandja (06/2012) } \\
\text { Pa, Palmwag (09/2010), Ta, Talismanis (12/2011), Ma, Mariental (06/2012), Ru, Rundu (01/2011),Wi, Windhoek (09/2010 and 01/2012). }\end{array}$} \\
\hline
\end{tabular}

arenavirus PCR, frozen lung tissue aliquots were homogenized and added to confluent Vero-E6 cells (ATCC CRL1586; American Type Culture Collection, Manassas, VA, USA) for virus isolation.

For genome sequencing, pellets from ultracentrifuged supernatant of infected cell cultures were lysed, and total RNA was purified. RNA was then subjected to randomprimed RT-PCR as described (11). Next-generation sequencing was performed by using a 454 Genome Sequencer Junior (Roche, Indianapolis, IN, USA), and results were aligned against the virus database by using blastn and blastx algorithms (http://blast.ncbi.nlm.nih.gov/Blast.cgi). Sequencing results matching arenavirus sequences were mapped to the LASV strain Josiah (GenBank accession no. AY628203). Because of low coverage for N27, an additional MiSeq (Illumina, San Diego, CA, USA) run was performed. De novo assembly of the data was performed with Geneious software (Biomatters, Auckland, New Zealand) (12). Sequence gaps or regions with low coverage were verified by Sanger sequencing (Applied Biosystems, Foster City, CA, USA). Genome segment outermost noncoding termini were sequenced after linkage by T4-RNA-Ligase (New England Biolabs, Ipswich, MA, USA) and RT-PCR amplification.

Of the 812 rodents and shrews tested (Table 1), arenavirus RNA was found in lung tissue samples of 4 Namaqua rock mice (Micaelamys [Aethomys] namaquensis), 3 from Okahandja (N73, N80, N85) and 1 from Mariental (N27). Sanger sequencing of PCR products from a 338-nt fragment of the viral polymerase gene confirmed arenaviruslike origin. Initial phylogenetic analysis showed that the Okahandja specimens were related to MWV, but the sample from Mariental was a highly divergent member of the genus Arenavirus (Figure 2, panel A). Cell culture isolation was performed with samples N27 and N73 and resulted in 2 novel arenavirus isolates: Mariental virus (MRTV) and Okahandja virus (OKAV), respectively.

The genomes of the 2 arenaviruses were investigated by using next-generation sequencing and RT-PCR Sanger sequencing. The genome data obtained for MRTV and OKAV showed a typical arenavirus nucleotide composition with the L segment (MRTV: 6,840 nt; OKAV: 7,170 nt) coding for RNA polymerase and matrix protein and the S segment (MRTV: 3,360 nt; OKAV: 3,379 nt) coding for glycoprotein and nucleocapsid protein. Table 2 shows the nucleotide and amino acid sequence identities of nucleocapsid and glycoprotein open reading frame with other Old World (i.e., Eastern Hemisphere locations such as Europe, Asia, Africa) representatives of genus Arenavirus. On the basis of the nucleocapsid amino acid identity, OKAV is most related to MWV (75.7\% identity). Furthermore, MRTV has the highest amino acid identity with IPPYV (71.4\% identity) and with Gbagroube, Lassa, Luna, and Mobala viruses ( $\approx 70 \%$ identity).

In the nucleocapsid-based phylogenetic tree, OKAV clusters with $100 \%$ bootstrap support with MWV detected in Myotomys unisulcatus rodents in South Africa (Figure 2, panel B), and MRTV forms a clade with IPPYV isolated from Praomys spp. in the Central African Republic. The bootstrap support of this monophyletic group of the tree lies at $56 \%$. The analysis of the glycoprotein open reading frame (Figure 2, panel C) leads to a similar result; OKAV shares the most recent common ancestor with MWV, and MRTV clusters with IPPYV but with a weaker bootstrap support. 

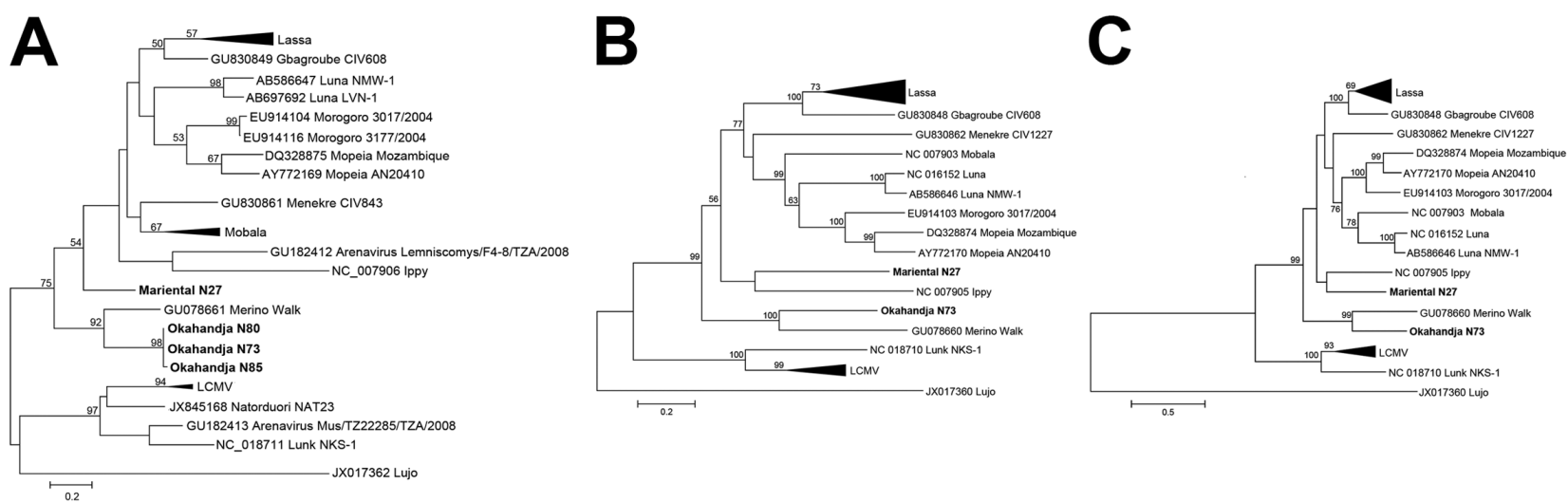

Figure 2. Phylogenetic analysis of Okahandja and Mariental viruses performed with maximum-likelihood method. A) Phylogenetic analysis of partial $\mathrm{L}$ segment sequence $(338 \mathrm{nt})$ of Okahandja and Mariental viruses obtained from reverse transcription PCR screening and performed with MEGA 6.0 (13) with maximum-likelihood method (general time reversible plus gamma model with 7 discrete Gamma categories; 1,000 bootstrap replications). Values at the branches are bootstrap values of the corresponding neighbor-joining tree (maximum composite likelihood method); values $<50 \%$ are not shown. Scale bar indicates an evolutionary distance of given substitutions per position in the sequence. B) Nucleocapsid open reading frame. C) Glycoprotein open reading frame. Scale bars indicate evolutionary distances of given substitutions per position in each sequence. LCMV, lymphocytic choriomeningitis virus.

\section{Conclusions}

We detected and isolated 2 novel arenaviruses in Namibia, OKAV and MRTV. OKAV clearly clustered in relationship with the MWV from southern Africa, but MRTV is a more divergent member of the Old World arenavirus clade. According to amino acid identity and phylogenetic analysis, MRTV was most closely related to IPPYV from the Central African Republic; however, the low bootstrap support precluded a stringent estimation of this closest relative.

These new strains comply with the arenavirus species definition (14) on the basis of amino acid differences in

\begin{tabular}{|c|c|c|c|c|c|}
\hline \multirow[b]{2}{*}{ Virus species } & \multirow{2}{*}{$\begin{array}{c}\text { S segment GenBank } \\
\text { accession no. }\end{array}$} & \multicolumn{2}{|c|}{ GPC } & \multicolumn{2}{|c|}{ NP } \\
\hline & & $\mathrm{nt}$ & aa & $\mathrm{nt}$ & aa \\
\hline MRTV (N27)† & KM272987 & & & & \\
\hline OKAV (N73)‡ & KM272988 & 64.6 & 68.9 & 64.9 & 66.1 \\
\hline Gbagroube & GU830848 & 66.7 & 73.6 & 64.1 & 69.9 \\
\hline Ippy & NC_007905 & 66.4 & 73.7 & 64.1 & 71.4 \\
\hline Lassa & AY628203 & 67.4 & 73.2 & 65.5 & 69.8 \\
\hline LCMV & AB261991 & 57.4 & 57.2 & 61.1 & 63.6 \\
\hline Lujo & JX017360 & 47.7 & 38.2 & 60.1 & 56.7 \\
\hline Luna & AB586646 & 66.4 & 73.2 & 64.2 & 69.5 \\
\hline Lunk & NC_018710 & 57.4 & 54.1 & 61.2 & 62.5 \\
\hline Menekre & GU830862 & 66.5 & 72.3 & 65.1 & 68.3 \\
\hline Merino walk & GU078660 & 63.8 & 70.2 & 64.9 & 67.3 \\
\hline Mobala & NC_007903 & 63.8 & 72.1 & 64.6 & 70.5 \\
\hline OKAV (N73) $\ddagger$ & $K M \overline{2} 272988$ & & & & \\
\hline Gbagroube & GU830848 & 62.0 & 66.3 & 61.1 & 65.7 \\
\hline Ippy & NC 007905 & 62.9 & 69.4 & 62.3 & 66.2 \\
\hline Lassa & AY628203 & 64.6 & 68.2 & 60.8 & 65.9 \\
\hline LCMV & AB261991 & 58.9 & 57.1 & 62.0 & 63.6 \\
\hline Lujo & JX017360 & 47.6 & 38.4 & 60.0 & 57.8 \\
\hline Luna & AB586646 & 62.5 & 67.1 & 63.0 & 67.2 \\
\hline Lunk & NC_018710 & 56.1 & 55.1 & 60.6 & 62.6 \\
\hline Menekre & GU830862 & 63.7 & 70.4 & 62.9 & 65.9 \\
\hline Merino walk & GU078660 & 64.7 & 76.1 & 68.2 & 75.7 \\
\hline Mobala & NC_007903 & 62.0 & 66.5 & 63.6 & 64.5 \\
\hline
\end{tabular}

*Identities are shown for glycoprotein and nucleocapsid open reading frames. Highest aa identity values are shown in boldface. S, small;

GPC, glycoprotein; NP, nucleocapsid protein; nt, nucleotide; aa, amino acid; LCMV, lymphocytic choriomeningitis virus; L, large segment.

†Genome composition of MRTV (N27): (Z: 69-371; RdRP: 6,820-473; GPC: 49-1,527; NP: 3,297-1,710). Accession numbers for MRTV (N27) virus sequences: L, KP867641; S, KM272987.

‡Genome composition of OKAV (N73): Z, 58-336; RdRP, 7,121-435; GPC, 51-1,553; NP, 3,315-1,627. Accession numbers for virus sequences for OKAV N73: L, KP867642; S, KM272988; for OKAV N80: L, KM234277; for OKAV N85: L, KM234278. 
nucleocapsid of $\geq 12 \%$ ( $>20 \%$ for both viruses), presence of specific host species, and existence of laboratory isolates. These properties indicate that MRTV and OKAV represent distinct arenavirus species.

These 2 viruses were found in the same host species located within a radius of $300 \mathrm{~km}$. MRTV was found in only 1 sample (of 266); OKAV was detected in samples from 3 animals. Although more unlikely for OKAV than for MRTV, the possibility of a spillover infection to $M$. $n a$ maquensis from a still unknown reservoir host cannot be ruled out for either virus.

The Namaqua rock mouse's habitat includes the tree and shrub savannahs of Namibia and most parts of southern Africa, including Namibia, South Africa, Botswana, Zimbabwe, and parts of Mozambique (15). These locations imply the possible occurrence of MRTV or OKAV in larger regions of the continent. Cell culture isolates and genomic sequence data are the first prerequisites for evaluating the public health relevance of these new viruses. Our findings extend the knowledge of geographic distribution and genetic diversity of arenaviruses in Africa.

\section{Acknowledgments}

We thank C. Chimimba for advice in small mammal systematics, P. Chimwamurombe for advice during preliminary screening for arenaviruses, and C. Priemer for technical support.

Trapping in Namibia was carried out under research permit nos. 1572/2011, 1666/2012 and 1794/2013, granted by Namibia's Ministry of Environment and Tourism.

This study was supported by Deutsche Forschungsgemeinschaft (grant KR1293/13-1) and by the Slovak Research and Development Agency under the contract no. DO7RP-0008-09.

Dr. Witkowski is a postdoctoral researcher at the Institute of Virology of the Charité Medical School in Berlin, Germany. His research interests are viral emerging infectious diseases on the African continent and their clinical impact and evolution.

\section{References}

1. Günther S, Lenz O. Lassa virus. Crit Rev Clin Lab Sci. 2004;41:339-90. http://dx.doi.org/10.1080/10408360490497456

2. Briese T, Paweska JT, McMullan LK, Hutchison SK, Street C, Palacios G, et al. Genetic detection and characterization of Lujo virus, a new hemorrhagic fever-associated arenavirus from southern Africa. PLoS Pathog. 2009;5:e1000455. http://dx.doi.org/ 10.1371/journal.ppat.1000455
3. Frame JD, Baldwin JM, Gocke DJ, Troupt AM. Lassa fever, a new virus disease of man from West Africa. Am J Trop Med Hyg. 1970;19:670-6.

4. N'Dilimabaka N, Berthet N, Rougeron V, Mangombi JB, Durand P, Maganga GD, et al. Evidence of lymphocytic choriomeningitis virus (LCMV) in domestic mice in Gabon: risk of emergence of LCMV encephalitis in Central Africa. J Virol. 2015;89:1456-60. http://dx.doi.org/10.1128/JVI.01009-14

5. Lecompte E, terMeulen J, Emonet S, Daffis S, Charrel RN. Genetic identification of Kodoko virus, a novel arenavirus of the African pigmy mouse (Mus (Nannomys) minutoides) in West Africa. Virology. 2007;364:178-83. http://dx.doi.org/10.1016/j.virol.2007.02.008

6. Coulibaly-N'Golo D, Allali B, Kouassi SK, Fichet-Calvet E, Becker-Ziaja B, Rieger T, et al. Novel arenavirus sequences in Hylomyscus sp. and Mus (Nannomys) setulosus from Côte d'Ivoire: implications for evolution of arenaviruses in Africa. PLoS ONE. 2011;6:e20893. http://dx.doi.org/10.1371/journal.pone.0020893

7. Ishii A, Thomas Y, Moonga L, Nakamura I, Ohnuma A, Hang'ombe B, et al. Novel arenavirus, Zambia. Emerg Infect Dis. 2011;17:1921-4. http://dx.doi.org/10.3201/eid1710.10452

8. Zapata JC, Salvato MS. Arenavirus variations due to host-specific adaptation. Viruses. 2013;5:241-78. http://dx.doi.org/10.3390/ v5010241

9. Joubert JJ, van der Merve CA, Lourens JH, Lecatsas G, Siegrühn C. Serological markers of hepatitis B virus and certain other viruses in the population of eastern Caprivi, Namibia. Trans R Soc Trop Med Hyg. 1991;85:101-3. http://dx.doi.org/10.1016/0035-9203(91)90176-Y

10. Vieth S, Drosten C, Lenz O, Vincent M, Omilabu S, Hass M, et al. RT-PCR assay for detection of Lassa virus and related Old World arenaviruses targeting the L gene. Trans R Soc Trop Med Hyg. 2007;101:1253-64. http://dx.doi.org/10.1016/j.trstmh.2005.03.018

11. Palacios G, Quan P, Jabado OJ, Conlan S, Hirschberg DL, Liu Y, et al. Panmicrobial oligonucleotide array for diagnosis of infectious diseases. Emerg Infect Dis. 2007;13:73-81. http://dx.doi.org/10.3201/eid1301.060837

12. Kearse M, Moir R, Wilson A, Stones-Havas S, Cheung M, Sturrock S, et al. Geneious Basic: an integrated and extendable desktop software platform for the organization and analysis of sequence data. Bioinformatics. 2012;28:1647-9. http://dx.doi.org/ 10.1093/bioinformatics/bts 199

13. Tamura K, Stecher G, Peterson D, Filipski A, Kumar S. MEGA6: Molecular Evolutionary Genetics Analysis version 6.0. Mol Biol Evol. 2013;30:2725-9. http://dx.doi.org/10.1093/molbev/mst197

14. Index of viruses - arenaviridae. In: Büchen-Osmond C, editor. The Universal Virus Database, version 4. New York: Columbia University, 2006 [cited 2014 Aug 11]. www.ncbi.nlm.nih.gov/ $\mathrm{ICTVdb} / \mathrm{Ictv} / \mathrm{fs}$ index.htm

15. Coetzee N, Griffin M, Taylor PJ. Aethomys namaquensis. In: The International Union for Conservation of Nature Red List of Threatened Species. Version 2014.1. 2014 [cited 2014 Aug 11]. www.iucnredlist.org

Address for correspondence: Peter T. Witkowski, Institute of Virology, Charité Medical School, Charitéplatz 1, 10117 Berlin, Germany; email: peter.witkowski@charite.de 